\title{
Rapid detection of the highly polymorphic $\beta$ globin framework by denaturing gradient gel electrophoresis
}

\author{
Monique Losekoot, Henny van Heeren, Jacky J Schipper, Piero C Giordano, \\ Luigi F Bernini, Riccardo Fodde
}

\begin{abstract}
The detection and identification of point mutations responsible for common human genetic diseases still represent a major technical problem especially when analysing genes with a large coding region or a heterogeneous spectrum of mutations or both. Before the advent of the polymerase chain reaction (PCR) this problem could be partially circumvented by the identification of haplotypes of restriction fragment length polymorphisms (RFLPs) distributed around and within the gene of interest. ${ }^{1}$ In informative families linkage between any given haplotype and the mutated gene can therefore be established, thus making the early and presymptomatic diagnosis of the disease feasible. ${ }^{12}$ Several RFLPs distributed over more than $60 \mathrm{~kb}$ have been described in the $\beta$ globin gene cluster. ${ }^{34}$ These polymorphisms have been observed to be non-randomly associated in different populations, thus giving rise to a limited number of haplotypes. Linkage disequilibrium has been shown between the haplotypes and $\beta$ thalassaemia mutations, which make them extremely useful for the early diagnosis of the thalassaemia syndromes. ${ }^{2}$ Within the $\beta$ globin gene itself, neutral substitutions have also been described. Extensive sequence analysis of normal and mutant $\beta$ globin genes has indicated the existence of four normal $\beta$ globin subhaplotypes, generally referred to as frameworks. ${ }^{45}$ These frameworks are particularly useful in linkage studies because they are located within the gene and are thus in tight linkage with the $\beta$ thalassaemia mutations.
\end{abstract}

The introduction of PCR has made the direct identification of single nucleotide substitutions, microdeletions, and insertions feasible. In particular the combination of PCR

Received 4 January 1992. Revised version accepted 14 February 1992. and subsequent analytical techniques, such as denaturing gradient gel electrophoresis $(\mathrm{DGGE})^{6}$ and single strand conformation polymorphisms (SSCPs), ${ }^{7}$ have proven particularly useful in the detection of mutations responsible for genetic diseases ${ }^{8-18}$ and in oncogene and tumour suppressor gene mutations. ${ }^{19}$ These techniques are used to predetermine the area of the gene in which a mutation is located; the same region can subsequently be amplified and sequenced without the necessity of cloning or sequencing the whole gene.

Apart from its applications for the direct detection of point mutations responsible for human genetic diseases, DGGE can also be used for the identification and detection of polymorphic nucleotide changes. ${ }^{20}$ Here we present the development of a one step procedure based on the analysis of PCR amplified material by DGGE to establish the $\beta$ globin framework rapidly. Two ampliprimers within the $\beta$ globin gene were designed spanning the nucleotides at IVS2 positions 16,74 , and 81 in a $190 \mathrm{bp}$ fragment (fig 1). Since the nucleotides present at these positions differ in all four frameworks, the electrophoretic pattern of the fragment on DGGE is characteristic of each framework. In a study of 85 unrelated Dutch subjects all four frameworks could be discriminated after analysis of the $190 \mathrm{bp}$ fragment by DGGE. In a preliminary study of 15 affected families of various ethnic origins the $\beta$ thalassaemia mutation could be linked to a DGGE haplotype and thus to a $\beta$ globin framework.

\section{Materials and methods} DNA SOURCE

Isolation of high molecular weight DNA was performed according to Miller et al. ${ }^{21}$

PCR AMPLIFICATION, DENATURING GRADIENT GEL ELECTROPHORESIS, AND DIRECT

SEQUENCING

PCR amplification was carried out as previously described. ${ }^{2223}$ The following ampliprimers were used: aB.GC: 5'-GCGGGCGG GGCGGGGGCACGGGGGGCGCGGCG GGCGGGGCGGGGGAGTGAGCTGCA CTGTGACAAGCTGCA-3'; IVS2: 5'-AA ACGATCCTGAGACTTCCA-3'. The gel apparatus and DGGE conditions were as described by Myers et $a l^{6}$ and Losekoot et al. ${ }^{9}$ Sequencing of PCR amplified DNA was per-
Figure 1 Schematic representation of the $\beta$ globin gene and its polymorphisms. Exon and introns are represented as filled and open boxes respectively. The position and orientation of the ampliprimers, aB.GC and IVS2, is shown. The nucleotides present at the various polymorphic sites in the different DGGE types/B globin frameworks are indicated below. The presence $(+)$ or absence $(-)$ of the restriction sites for HgiAI, AvaII, and BamHI, used to determine the $\beta$ globin framework by RFLP analysis, is also indicated. 


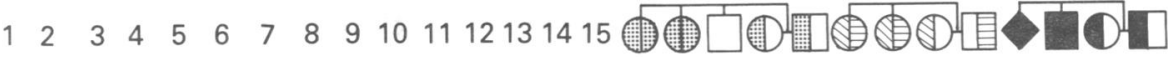

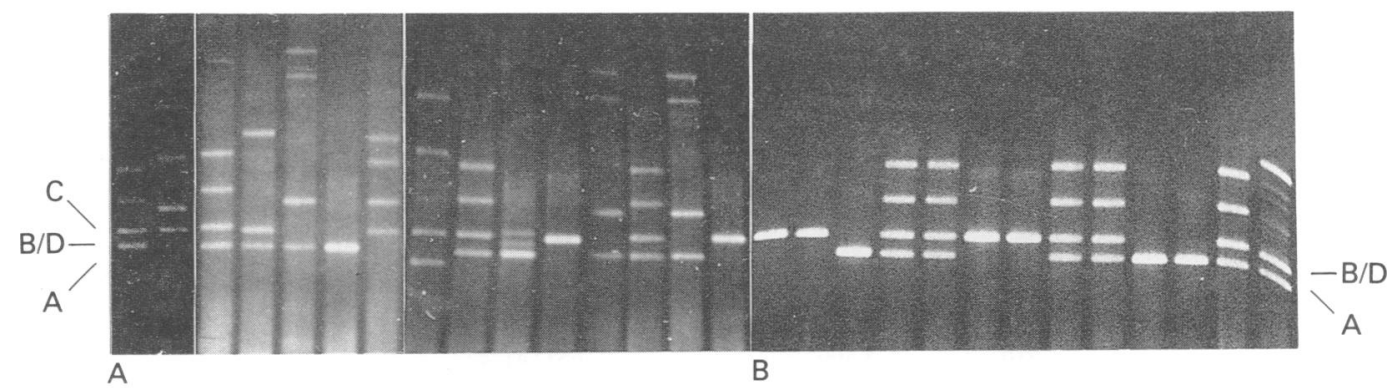

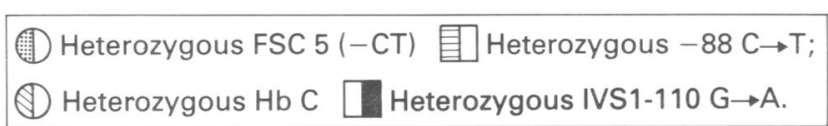

Figure 2 (A) Ethidium bromide stained $8 \%$ polyacrylamide gel containing a linearly increasing $35-60 \%$ gradient of denaturant. $\beta$ globin fragments from unrelated subjects, amplified with primers aB.GC and IVS2, were loaded. The point along the gradient where the different homoduplexes migrate is indicated at the side of the picture. Lanes: $1, A B ; 2, B C ; 3, A B ; 4, A D ; 5, A C ; 6, A A ; 7, D C ; 8, A^{*} B ; 9, A B ; 10, A I V S 2-1(G \rightarrow A) ; 11, D D ; 12, A C ;$ $13, A B ; 14, A C ; 15, B B$. (B) DGGE patterns from members of three different families corresponding from left to right with families 12,13 , and 8 from table 2 . DGGE type from left to right: $B B, B B, A A, A B, A B, B B, B B$, $A B, A B, A A, A A, A B, A D$.

formed using the 'depleted' primer approach as described by Gyllensten and Erlich. ${ }^{24}$

\section{Results}

DNA from 85 unrelated Caucasian subjects was amplified with ampliprimers aB.GC and IVS2 (fig 1). Analysis of the $190 \mathrm{bp}$ fragment on a $35-60 \%$ denaturing gradient gel showed nine different patterns because of the combination of four different alleles, designated $A$, $B, C$, and $D$. As shown in fig 2 the homoduplexes corresponding to alleles $A$ and $C$ are easily resolvable, while the homoduplexes $B$ and $\mathrm{D}$ comigrate at the same position along the denaturing gradient. However, the heteroduplexes corresponding to the $A / B, A / D, C / B$, and $C / D$ hybrid molecules migrate at different rates along the gel (fig $2 \mathrm{~A}$, lanes $3,4,2$, and 7 respectively), allowing the discrimination of all four alleles. Homozygotes $\mathrm{BB}$ or $\mathrm{DD}$ can therefore be resolved by generating artificial 'PCR heterozygotes' with either an AA or CC homozygote (fig 2A, lanes 1 and 2).

The correspondence between the electrophoretic pattern on DGGE and the $\beta$ globin framework was established by direct sequencing of several samples with different DGGE types (data not shown) and showed that alleles $A, B, C$, and D correspond to framework 1,2 , 3 , and 3 Asian respectively (fig 1 ).

The frequency of the different genotypes in a sample of 85 Caucasian (Dutch) subjects is given in table 1 . The $A B$ and $A A$ genotypes are the most frequent (26 and 24 respectively), while 14 subjects were $B B$, nine $A C$, five $A D$ and five BC. Neither the DD nor the BD genotypes were represented and the $C C$ and CD genotypes were rare (found in only one subject). The difference between the observed and the expected frequencies of the DGGE genotypes was not significant $\left(\chi_{2}^{2}=2 \cdot 36\right.$, $0.1<\mathrm{p}<0.5$ ).

The analysis of $15 \beta$ thalassaemia families of different ethnic origin showed that the DGGE haplotype is inherited in a mendelian fashion. Furthermore the DGGE haplotype, and thus the $\beta$ globin framework, in which the $\beta$ thalassaemia mutation is located could be established in all families (table 2, fig 2B).

During this screening an abnormal electrophoretic pattern, that is, not consistent with any of the four haplotypes, was found in a subject of Moroccan origin (fig 2A, lane 8). Direct sequencing showed a $T \rightarrow G$ substitution at position 26 of the second intron on a framework 1 (DGGE type A) chromosome, designated $A^{*}$. Since this mutation does not segregate with any phenotypic abnormality in this family, it was considered a neutral substitution. The $T \rightarrow G$ substitution at position IVS2-26 was not found in any of the other $15 \beta$ thalassaemia families nor in the 85 normal Dutch subjects.

Furthermore, we observed an additional electrophoretic pattern corresponding to a $\beta$ thalassaemia mutation (IVS2-1 G $\rightarrow A$ ), which is also included in the $190 \mathrm{bp}$ fragment (fig $2 \mathrm{~A}$, lane 10). In this case the heteroduplexes migrate at a lower level in the gel, while the homoduplexes do not separate under these conditions, neither do the heteroduplexes from the AD type.

Table 1 Frequency of the different genotypes $\left(\chi_{2}^{2}=2 \cdot 36,0 \cdot 1<p<0 \cdot 5\right)$ in the Dutch population.

\begin{tabular}{lcc}
\hline Genotype & Observed & Expected \\
\hline AA & 24 & $22 \cdot 8$ \\
BB & 14 & $10 \cdot 2$ \\
CC & $1^{*}$ & $0 \cdot 8$ \\
AB & 26 & $30 \cdot 6$ \\
AC & 9 & $8 \cdot 8$ \\
AD & $5^{*}$ & $2 \cdot 7$ \\
BC & 5 & $5 \cdot 9$ \\
BD & $5^{*}$ & $2 \cdot 0$ \\
DD & $1^{*}$ & $0 \cdot 5$ \\
Total & $-^{*}$ & $0 \cdot 1$ \\
\hline
\end{tabular}

The frequencies of the classes indicated with an asterisk have been pooled. 
Table 2 DGGE haplotype of a limited number of $\beta$ thalassaemia mutations.

\begin{tabular}{|c|c|c|c|c|c|}
\hline Family & Country of origin & Mutation & $\begin{array}{l}\text { DGGE } \\
\text { haplotype }\end{array}$ & Framework & $\begin{array}{l}\text { Orkin } \\
\text { et } a l^{*}\end{array}$ \\
\hline & Netherlands & $\begin{array}{l}\beta \text {-thal } \dagger \\
\text { Hb E }\end{array}$ & $\begin{array}{l}\mathbf{A} \\
\mathbf{B}\end{array}$ & $\begin{array}{l}1 \\
2\end{array}$ & $\overline{2}$ Asia \\
\hline F2 & China & $\begin{array}{l}-88 \mathrm{C} \rightarrow \mathrm{T} \\
\text { FSC } 41-42(-\mathrm{CTTT})\end{array}$ & D & $\begin{array}{l}3 \mathrm{~A} \\
1\end{array}$ & $\overline{1}$ Asia \\
\hline F3 & Turkey & FSC 8 (-AA) (hom) & $\mathrm{C}$ & 3 & $3 \mathrm{Med}$ \\
\hline F4 & Netherlands & $-88 \mathrm{C} \rightarrow \mathrm{T}$ & $\mathbf{A}$ & 1 & - \\
\hline F5 & Morocco & FSC $5(-\mathrm{CT})$ (hom) & $\mathbf{B}$ & 2 & - \\
\hline F6 & Turkey & IVS1-110 G $\rightarrow \mathrm{A}(\mathrm{hom})$ & $\mathbf{A}$ & $\overline{1}$ & $1 \mathrm{Med}$ \\
\hline \multirow[t]{2}{*}{ F7 } & Morocco & Hb S & B & 2 & \\
\hline & & IVS1-1 $(\mathbf{G} \rightarrow \mathbf{A})$ & B & 2 & 2 Med \\
\hline F8 & Turkey & IVS1-110 G $\rightarrow A$ (hom) & A & 1 & $1 \mathrm{Med}$ \\
\hline F9 & Netherlands & IVS1-1 $(\mathbf{G} \rightarrow \mathbf{A})$ & B & 2 & 2 Med \\
\hline F10 & Nethe 'ands & FSC $41-42(-$ CTTT $)$ & A & 1 & 1 Asia \\
\hline F11 & Nether iands & Codon $39(\mathrm{C} \rightarrow \mathrm{T})$ & A & 1 & 1 Med \\
\hline \multirow[t]{2}{*}{ F12 } & Surinam & $\mathrm{Hb} \mathrm{C}$ & B & 2 & - \\
\hline & (Negro) & $-88 \mathrm{C} \rightarrow \mathrm{T}$ & B & 2 & - \\
\hline F13 & Unknown & FSC 5 (-CT) (hom) & B & 2 & - \\
\hline F14 & Iran & IVS $1-5(G \rightarrow C)$ & A & 1 & - \\
\hline \multirow[t]{2}{*}{ F15 } & Surinam & FSC $8 / 9(+G)$ & A & 1 & - \\
\hline & (Pakistan) & IVS1-5 (G $\rightarrow$ C) & D & $3 \mathbf{A}$ & - \\
\hline
\end{tabular}

* The framework is indicated on which Orkin et a ${ }^{20}$ found this mutation in the Asian (Asia) or Mediterranean (Med) populations. $\dagger$ The molecular nature of the mutation has not been established yet.

\section{Discussion}

The identification of sequence heterogeneity by restriction fragment length polymorphisms has had a great impact on studies of genetic linkage and the diagnosis of genetic diseases. However, only a limited amount of the sequence heterogeneity can be recognised by RFLP analysis, but denaturing gradient gel electrophoresis allows the detection of any single base change in an early melting domain. Here we show that DGGE can be used to detect three polymorphic base changes in a single $190 \mathrm{bp}$ fragment spanning the $5^{\prime}$ half of the second intron of the $\beta$ globin gene. DGGE analysis of this highly polymorphic intragenic fragment provides an attractive alternative to RFLP analysis; it is a rapid, one step procedure and a large number of samples can be screened simultaneously in a non-radioactive way. This approach has proved extremely useful not only in the detection of previously identified polymorphisms, but it can also be applied to detect unknown polymorphisms and to screen the polymorphic content of a previously uncharacterised sequence.

The frequencies of the $\beta$ globin frameworks in the Dutch population are comparable to those in the Mediterranean population ${ }^{4}$ (framework $152 \% v 53 \%$, framework $235 \% v$ $28 \%$, and framework $310 \% v 19 \%$ in the Dutch and Mediterranean populations, respectively), excluding the presence of framework 3 Asian at a low frequency $(3 \%)$ in the autochthonous Dutch population. This is most probably the result of gene flow from Asiatic (Indonesian) populations which occurred during the colonial period.

The $\beta$ thalassaemia mutations were found on the same $\beta$ globin framework as described by Orkin $e t a l^{5}$ for the corresponding ethnic group (table 2). The Dutch Hb E and FSC 41-42 (-CTTT) mutations were found on the same $\beta$ framework as in the Asian population, while the Dutch IVS1-1 $(\mathrm{G} \rightarrow \mathrm{A})$ and codon 39 $(\mathrm{C} \rightarrow \mathrm{T})$ mutations were found on the same framework as in the Mediterranean population. This can be explained by assuming that the $\beta$ thalassaemia mutation/chromosome was imported from these respective populations. Not all mutations were found on the same framework: the $-88 \mathrm{C} \rightarrow \mathrm{T}$ mutation was found on framework 1 in a Dutch family, on framework 3 Asian in an Asian family, and on framework 2 in a Surinam-Negro family, while the IVS1-5 G $\rightarrow$ C mutation was found on two different frameworks ( 1 and 3 Asian). Analysis of the different frameworks by DGGE can thus be used to exclude the single origin of $\beta$ globin gene mutations.

The information provided by the framework polymorphism can also be applied, in informative $\beta$ thalassaemia families, to perform prenatal diagnosis by linkage analysis. With this intragenic polymorphism misdiagnosis owing to meiotic crossovers is reduced to an insignificant level. However, the number of cases in which the diagnosis is possible remains in the order of $50 \%$ (polymorphic information content value for the Dutch population is $0.524^{1}$ ). Greater heterogeneity (in mixed populations for instance) increases the chance of locating in a couple at risk a $\beta$ globin mutation on a particular haplotype. The analysis of our 11 'at risk' families shows that prenatal diagnosis was or could be possible in four cases with the aid of the framework screening and haematology only, while in six families homozygosity for $\beta$ thalassaemia can be excluded in $50 \%$ of the pregnancies. The use of this DGGE polymorphism can therefore help other commonly used PCR based technologies in the early and rapid detection of point mutations responsible for $\beta$ thalassaemia syndromes.

1 Botstein D, White RL, Skolnick M, Davis RW. Construction of a genetic linkage map in man using restriction frament length polymorphisms. Am 7 Hum Genet 1980;32:314-31.

2 Kazazian HH Jr, Philips JA, Boehm CD, Vik TA, Mahoney MJ, Ritchey AK. Prenatal diagnosis of $\beta$ thalassemia by amniocentesis: linkage analysis using multiple polymorphic restriction endonuclease sites. Blood 1980;56:92630 .

3 Jeffreys AJ. DNA sequence variants in the ${ }^{G_{\gamma-},{ }^{A} \gamma-, \delta \text { - and }}$ $\beta$-globin genes of man. Cell 1979;18:1-10.

4 Antonarakis EA, Kazazian HH Jr, Orkin SH. DNA polymorphism and molecular pathology of the human globin morphism and molecular pathology of

5 Orkin SH, Kazazian HH Jr, Antonarakis SE, et al. Linkage of $\beta$-thalassemia mutations and $\beta$-globin gene polymorof $\beta$-thalassemia mutations and $\beta$-globin gene polymor-
phisms in human $\beta$-globin gene cluster. Nature phisms in human 
6 Myers RM, Maniatis T, Lerman LS. Detection and localization of single base changes by denaturing gradient gel
electrophoresis. Methods Enzymol 1987;155:501-27.

7 Orita M, Iwahana H, Kanazawa H, Hayashi K, Sekiya T. Detection of polymorphisms of human DNA by gel electrophoresis as single-strand conformation polymor phisms. Proc Natl Acad Sci USA 1989;86.2766-70.

8 Cai SP, Kan YW. Identification of the multiple $\beta$-thalassemia mutations by denaturing gradient gel electrophoresis. f Clin Invest 1990;85:550-3.

9 Losekoot M, Fodde R, Harteveld CL, van Heeren H, Giordano PC, Bernini LF. Denaturing gradient gel electrophoresis and direct sequencing of PCR amplified genomic DNA: a rapid and reliable diagnostic approach to $\beta$ thalassaemia. Br f Haematol 1990;76:269-74.

10 Cariello NF, Scott JK, Kat G, Thilly WG, Keohavong P. Resolution of a missense mutation in human genomic DNA by denaturing gradient gel electrophoresis and direct sequencing using in vitro DNA amplification: direct sequencing using in vitro DNA amplificat

11 Attree O, Vidaud D, Vidaud M, Amselem S, Lavergne JM, Goossens $M$. Mutations in the catalytic domain of human coagulation factor IX: rapid characterization by direct genomic sequencing of DNA fragments displaying an altered melting behavior. Genomics 1989;4:266-72.

12 Kogan S, Gitschier J. Mutations and polymorphism in the factor VIII gene discovered by denaturing gradient gel electrophoresis. Proc Natl Acad Sci USA 1990;87:20926.

13 Traystman $M D$, Higuchi M, Kasper CK, Antonarakis SE, Kazazian $\mathrm{HH} \mathrm{Jr}$. Use of denaturing gradient gel electrophoresis to detect point mutations in the factor VIII gene. Genomics 1990;6:293-301.

14 Finkelstein JE, Francomano CA, Brusilow SW, Traystman $M D$. Use of denaturing gradient gel electrophoresis for detection of mutation and prospective diagnosis in late onset ornithine transcarbamylase deficiency. Genomics 1990;7:167-72.
15 Vidaud M, Fanen P, Martin J, Ghanem N, Nicolas $S$, Goossens $M$. Three point mutations in the CFTR gene in French cystic fibrosis patients: identification by denaturFrench cystic fibrosis patients: identification by denatur-

16 Devoto M, Ronchetto P, Fanen P, et al. Screening for nondeltaF508 mutations in five exons of the cystic fibrosis transmembrane conductive regulator (CFTR) gene in Italy. Am f Hum Genet 1991;48:1127-32.

17 Losekoot M, Fodde R, van Heeren H, Harteveld CL, Giordano PC, Bernini LF. A novel frameshift mutation FSC $47(+A)$ ] causing $\beta$-thalassemia in a Surinam patient. Hemoglobin 1990;14:467-70.

18 Losekoot M, Fodde R, Harteveld CL, et al. Homozygous $\mathrm{B}^{+}$thalassaemia owing to a mutation in the cleavagepolyadenylation sequence of the human $\beta$ globin gene. $\mathcal{f}$ Med Genet 1991;28:252-5.

19 Orita M, Suzuki Y, Sekiya T, Hayashi K. Rapid and sensitive detection of point mutations and DNA polymorphisms using the polymerase chain reaction. Genomics phisms using

20 Noll WW, Collins M. Detection of human DNA polymorphisms with a simplified denaturing gradient gel electrophoresis technique. Proc Natl Acad Sci USA 987;84:3339-43

21 Miller SA, Dykes DD, Polesky HF. A simple salting out procedure for extracting DNA from human nucleated cells. Nucleic Acids Res 1988;16:1215.

22 Giordano PC, Fodde R, Losekoot M, Bernini LF. Design of a programmable automatic apparatus for the DNA polymerase chain reaction. Technique 1989;1:16-20.

23 Losekoot M, Fodde R, Giordano PC, Bernini LF. A novel $\delta^{0}$-thalassemia arising from a frameshift insertion, detected by direct sequencing of enzymatically amplified DNA. Hum Genet 1989;83:75-8.

24 Gyllensten UB, Erlich HA. Generation of single-stranded DNA by the polymerase chain reaction and its application to direct sequencing of the HLA-DQA locus. Proc Natl to direct sequencing of the HLA
Acad Sci USA 1988;85:7652-6. 